\title{
Concurrent intracerebral and intramedullary spinal tuberculomas in an immunocompetent individual
}

\author{
Srikanth Prasad, Muralidhar Varma, Sudha Vidyasagar
}

Department of Internal Medicine, Kasturba Medical College, Manipal, Karnataka, India

Correspondence to Dr Srikanth Prasad, srikanthprasadrao@yahoo.com

Accepted 31 August 2015
CrossMark

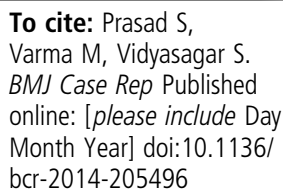

\section{DESCRIPTION}

A 28-year-old Indian man presented to us with progressive weakness of both lower limbs of 1 month duration. His physical examination revealed spastic paraparesis with a power of $2 / 5$, bilateral lower limb hyper-reflexia and positive Babinski sign. His routine blood tests were within normal limits and he was negative for HIV ELISA. His chest X-ray showed bilateral multiple miliary shadows (figure 1). MRI of the spine performed for the evaluation of paraparesis showed multiple intramedullary ring enhancing lesions extending from D6 level up to the conus, with perifocal oedema (figure 2). MRI of the brain showed multiple welldefined ring enhancing lesions with perilesional oedema scattered diffusely in the cerebral hemispheres, brainstem and cerebellum (figure 3). The patient was diagnosed as a case of disseminated tuberculosis with multiple intramedullary and intracerebral tuberculomas. He was started on antitubercular therapy with rifampicin, isoniazid, pyrazinamide and ethambutol along with a short course of steroids. He improved with the treatment and at the end of 1 year of follow-up regained almost complete neurological function; his MRI showed near complete resolution of the tuberculomas.

Central nervous system (CNS) tuberculosis accounts for $10 \%$ of all cases of tuberculosis. ${ }^{1}$ Of this, the ratio of cranial to spinal tuberculosis is $42: 1$. $^{2}$ Simultaneous occurrence of intramedullary and intracerebral tuberculomas is very rare and there are only a few case reports describing these coexisting lesions. Extensive disseminated tuberculosis is common in the setting of HIV infection.
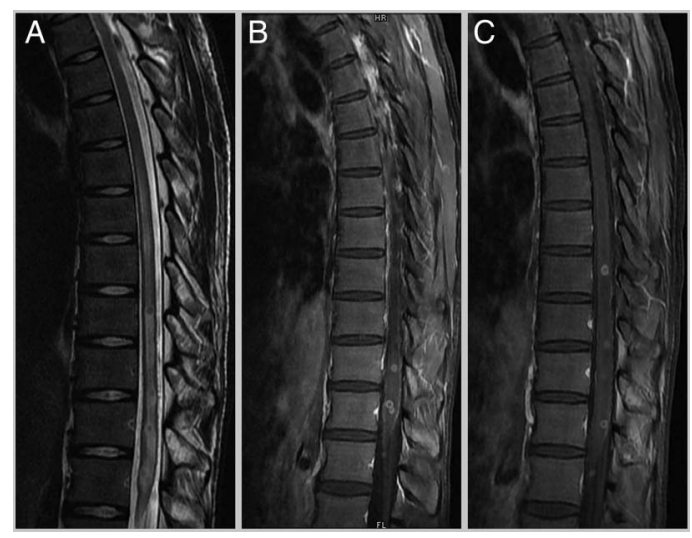

Figure 2 Sagittal MRIs of the spine depicting multiple intramedullary ring enhancing lesions scattered within the dorsal and lumbar spinal cord (extending from D6 level up to the conus).

But our patient was HIV negative and this makes it a rare occurrence. CNS tuberculosis is acquired either through haematogenous spread or direct spread from a pulmonary focus. Our patient had miliary tuberculosis, which might have been the focus for CNS infection. MRI has revolutionised the diagnosis of tuberculomas and has helped in avoiding invasive procedures for diagnosis. MRI can diagnose tuberculoma with reasonable certainty and antitubercular treatment may be instituted based on these findings, as was done in our case. ${ }^{3}$ This case highlights the importance of complete screening in suspected cases of disseminated tuberculosis for institution of early and adequate therapy to obtain satisfactory results.

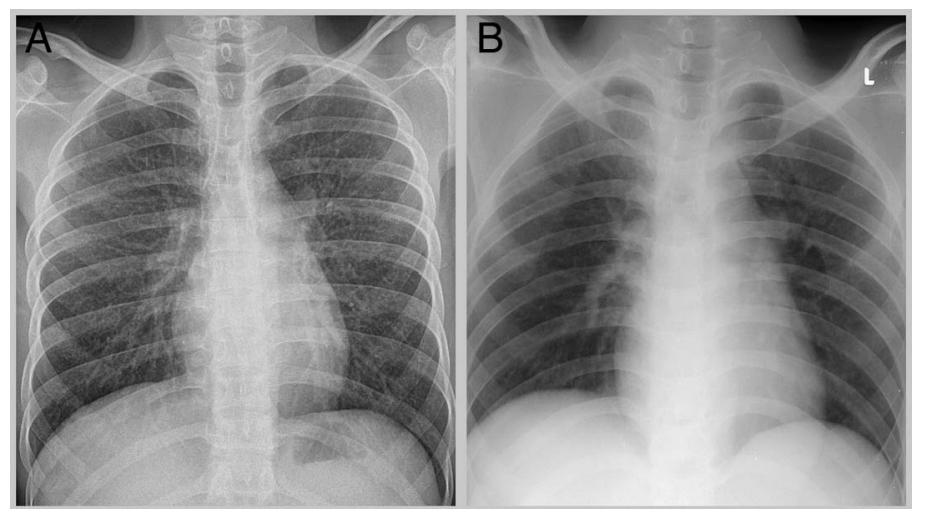

Figure 1 Chest $\mathrm{X}$-ray showing $(\mathrm{A})$ bilateral diffuse miliary shadows at diagnosis and $(\mathrm{B})$ resolution of the miliary mottling after treatment with antitubercular drugs. 

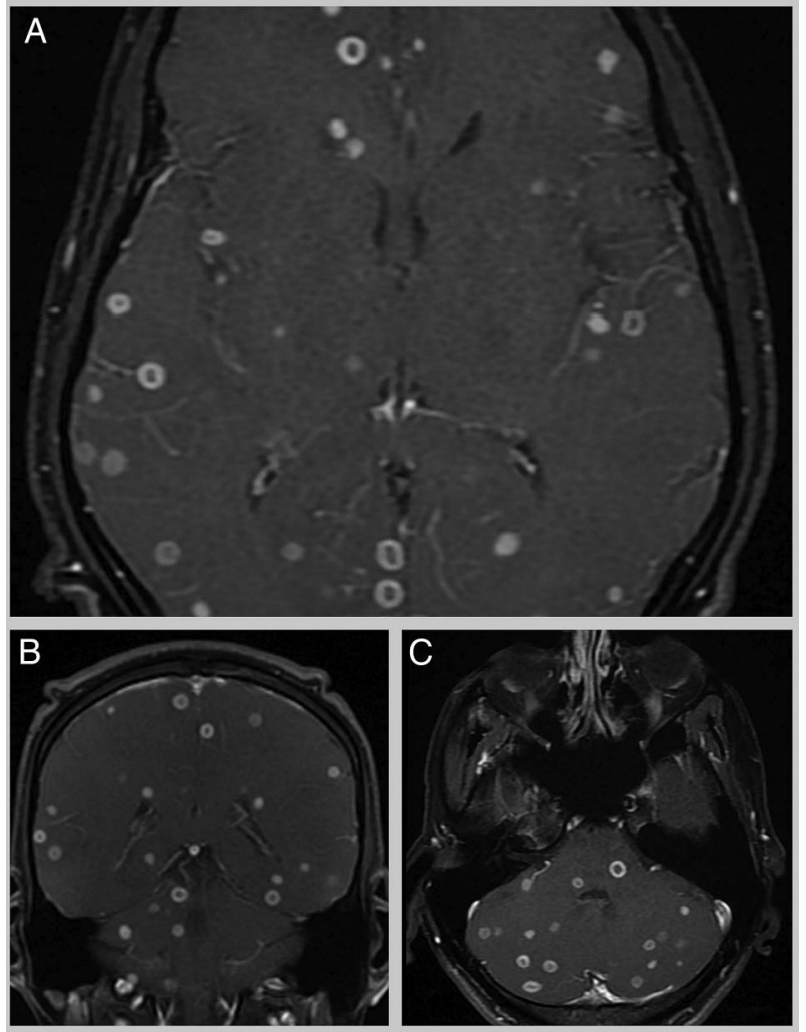

Figure 3 Axial and coronal MRIs of the brain depicting multiple ring enhancing lesions scattered in the cerebral hemispheres, brainstem and cerebellum, which are hypointense with a hyperintense rim on T2-weighted sequences.

\section{Learning points}

- Concurrent occurrence of intramedullary and intracerebral tuberculomas is very rare.

- A high index of suspicion and complete screening is essential in all cases of suspected disseminated tuberculosis.

- MRI is a very sensitive and useful tool for the diagnosis of central nervous system tuberculosis.

Contributors SP and MV were involved in the conception, design and acquisition of the images, and drafting of the manuscript. MV and SV were involved in revising it critically for important intellectual content. SV was involved in the final approval of the version published.

Competing interests None declared.

Patient consent Obtained.

Provenance and peer review Not commissioned; externally peer reviewed.

\section{REFERENCES}

1 Garg RK. Tuberculosis of the central nervous system. J Postgrad Med 1999;75:133-40.

2 Citow JS, Ammirati M. Intramedullary tuberculoma of the spinal cord: case report. Neurosurgery 1994;35:327-30.

3 Garg RK, Sinha MK. Multiple ring-enhancing lesions of the brain. J Postgrad Med 2010;56:307-16.

Copyright 2015 BMJ Publishing Group. All rights reserved. For permission to reuse any of this content visit

http://group.bmj.com/group/rights-licensing/permissions.

BMJ Case Report Fellows may re-use this article for personal use and teaching without any further permission.

Become a Fellow of BMJ Case Reports today and you can:

- Submit as many cases as you like

- Enjoy fast sympathetic peer review and rapid publication of accepted articles

- Access all the published articles

- Re-use any of the published material for personal use and teaching without further permission

For information on Institutional Fellowships contact consortiasales@bmjgroup.com

Visit casereports.bmj.com for more articles like this and to become a Fellow 